\title{
GOFFMAN, MAL-ENTENDIDOS \\ E RISCOS INTERACIONAIS
}

\section{Gilberto Velho}

Já no seu primeiro livro, The presentation of self in everyday life (1959), Goffman faz uma breve citação de trabalho de Gustav Ichheiser, psicólogo social e fenomenólogo judeu austríaco radicado nos Estados Unidos, fugido do nazismo. Este autor teve uma vida pessoal e profissional extremamente difícil e é, até hoje, relativamente pouco conhecido. Suas dificuldades de exilado foram agravadas por circunstâncias pessoais que incluíram um internamento de onze anos em instituição psiquiátrica nos Estados Unidos. Suas relações com o mundo acadêmico foram precárias, jamais obtendo uma inserção profissional que the garantisse estabilidade e segurança no trabalho. Ainda assim, deixou alguns trabalhos de grande atualidade. ${ }^{1}$ Quando comecei a ler o artigo "Misunderstandings in human relations: a study in false social percep-

Artigo recebido em maio/2008

Aprovado em julho/2008 tion" (Ichheiser, 1949), pareceu-me provável que a importância de sua leitura e, talvez, de outros trabalhos desse intelectual austríaco, para Goffman, tivesse sido maior do que apenas a referida citação poderia fazer crer. Icheisser focaliza a questão do mal-entendido nas relações entre indivíduos, analisando situações sociais e processos de interação ilustrativos desses desencontros, mais ou menos dramáticos, envolvendo sociologia e psicologia social. Em seguida, contactei Howard S. Becker, colega de Goffman no Departamento de Sociologia da Universidade de Chicago, no final dos anos de 1940 e início da década seguinte. Ele me confirmou que o texto de Ichheiser fora conhecido e lido por aquela famosa geração acadêmica que incluía, além de Becker e Goffman, outros profissionais que viriam a ter destaque, como Anselm Strauss e Eliot Freidson, embora o texto apresentasse, em sua opinião, maior interesse direto para as preocupações de Goffman. 
A Escola de Chicago, na realidade, é uma denominação ou rótulo que engloba grande heterogeneidade e diversidade. Surgiu, originalmente, no Departamento de Sociologia e Antropologia da Universidade de Chicago, mas as pessoas que ali estudaram foram se espalhando não só pelos Estados Unidos, mas também por outros países. Assim, é preciso certo cuidado para não imaginar que se trata de uma escola em Chicago, simplesmente. Outro cuidado que deve ser tomado é distinguir a Escola de Chicago socioantropológica da econômica que tem, por sua vez, marcas muito fortes que a distinguem. O Departamento de Sociologia e Antropologia dividiu-se em 1929, mas houve continuidade em relação a certos modos de fazer ciência social, como a preocupação fundamental com o trabalho de campo e, em geral, a valorização da pesquisa. Esta característica se oporia a correntes mais voltadas para discussões eminentemente teóricas e metodológicas (Bulmer, 1984; Becker, 1996). Além disso, num período desde o final do século XIX até o início da segunda metade do século XX, houve transformações que acompanharam as etapas e os desdobramentos das gerações que se sucederam. Na Escola de Chicago, como em outras tradições intelectuais, há continuidades, mudanças e mesmo rupturas. A geração de pós-Segunda Grande Guerra Mundial foi das mais inovadoras e criativas. Certamente, não há nada parecido com uma "unidade de doutrina", mas uma rica variedade de estilos e trajetórias. Há diferentes graus de proximidade e afinidade intelectual e pessoal entre os membros dessa geração (sobre a Escola de Chicago ver, também, Valladares, 2005).

Estou convencido de que para compreender melhor tanto a obra de Goffman como o que se costuma definir como interacionismo, particularmente no caso de sua geração, é importante pensar nas relações entre as influências de Georg Simmel, de William James, dos mestres de Chicago, como William Thomas e G. H. Mead, dos seus professores diretos como Louis Wirth, Herbert Blumer, Everett Hughes, Lloyd Warner, assim como da fenomenologia. Esta se manifestará em diferentes combinações, variando de autor para autor, com o pragmatismo e com o interacionismo de linhagem originalmente simmeliana. Além da mencionada citação de Gustav Ichheiser, Goffman, em fase bem posterior de sua carreira, em Frame analysis (1974), volta-se para a obra de Alfred Schutz, outro feno- menólogo austríaco fugido do nazismo, com obra de maior repercussão do que a de Ichheiser sobre, entre outros pontos, as noções de provincias de significado e múltiplas realidades. Foi, ao contrário de seu compatriota, doublê de scholar reconhecido e bemsucedido homem de negócios (Schutz, 1979). Goffman aproxima Schutz de William James, tecendo considerações sobre a dificuldade de fixar a noção de realidade, mesmo socialmente construída, problematizando a questão das fronteiras e as passagens entre os diferentes mundos. Retoma a questão que James já apresentara, no capítulo “The perception of reality", em Principles of reality: "em que circunstâncias pensamos que algo é real?" ["under what circunstances do we think things are real?”] (1950, pp. 283-324).

Em praticamente todo o desenvolvimento de Frame analysis, na busca de instrumentos analíticos capazes de dar conta da percepção, da construção e da ação na realidade, Goffman parte de reflexões levantadas por James, Thomas e Schutz, numa interessante associação entre pragmatismo e fenomenologia. A própria noção de frame, de difícil tradução (quadro, forma etc.) é conseqüência da leitura desses autores e, por outro lado, de Gregory Bateson (1972).

Quanto ao artigo de Ichheiser, reiterando, creio que teve importante repercussão na obra de Goffman desde o início de sua carreira, embora Becker, em contato pessoal, considere difícil avaliar sua extensão, devido às múltiplas influências e reinvenções que encontramos na obra de seu colega. A idéia básica do artigo é que existe uma permanente possibilidade de desentendimento e desencontro nas interações entre atores sociais. Ou seja, os indivíduos desempenhando papéis estão sempre procurando expressar-se e, para que isso tenha sucesso sociopsicológico, é necessário que os atores com quem estejam interagindo se impressionem com o que está sendo transmitido. A interação e seu desenvolvimento dependem, portanto, de um compartilhamento e/ou cumplicidade nos termos do que William Thomas chamou de definição de situação (Thomas, 1966). A possibilidade permanente de conflito, conforme Simmel (1964 e 1971), está sempre presente e poderá explicitar-se quando houver não só antagonismo de interesses de qualquer nível mas também, seguindo Ichheiser, mal-entendidos, em que se caracteriza um desencontro afetivocognitivo entre os atores sociais. Assim, a expressão 
de algum sentimento, vontade ou transmissão de informação em geral está sujeita a uma possibilidade de riscos de recepção e percepção do outro. Todas as interações, da díade simmeliana até as redes sociais mais complexas, dependem de compreensões (understandings) básicas que permitam desde uma sociabilidade elementar até o compartilhamento de projetos coletivos mais amplos. Estes, por sua vez, são mais do que o somatório de condutas individuais organizadas para atingir finalidades específicas, pois dependem de acordos e ajustes entre indivíduos e grupos, conforme a clássica definição de Schutz (1979). Nessa linha de reflexão, a vida social é um permanente processo de negociação da realidade. Por outro lado, para fenomenólogos como Schutz, a realidade é um processo socialmente construído e só assim pode ser entendida e analisada. Portanto, pode-se dizer que a construção social da realidade se dá via uma negociação mais ou menos explícita entre os atores envolvidos. Certamente há distâncias e diferenças entre o que está implícito e uma verbalização que expresse, de modo consciente, interesses, desejos e vontades. Para Ichheiser existe, sempre, a possibilidade de uma falsa percepção social no processo de interação. Trata-se de uma preocupação que atravessa, de diferentes maneiras, toda a obra de Goffman. A apresentação do self é construída para enviar mensagens e informações que transmitam determinada imagem desejável sob o ponto de vista do ator. $\mathrm{O}$ famoso texto sobre Preedy, turista inglês em praia espanhola, que Goffman utiliza, extraído de um livro de William Sanson, ilustra de modo inesquecível essa análise de que "A informação a respeito do indivíduo serve para definir a situação, tornando os outros capazes de conhecer antecipadamente o que ele esperará deles e o que dele podem esperar. Assim informados, saberão qual a melhor maneira de agir para dele obter uma resposta desejável" (Goffman, 1959).

Mas o risco de falsa percepção e mal-entendido é permanente, pairando como um fantasma sobre toda e qualquer interação. Poder-se-ia dizer que se trata de um risco inerente à vida social como um todo. A noção de performance é fundamental nessa reflexão, remetendo também às de palco (stage) e bastidores (backstage). Creio que a possibilidade de mal-entendido, como formulado por Ichheiser, estimula grande parte da reflexão goffmaniana sobre performance. Sabemos também da forte presença de Sartre na trajetória intelectual de Goffman, subli- nhando a dimensão dramática e ameaçadora da presença do outro como constitutiva das relações sociais. Convém lembrar a sua origem canadense e suas fortes relações com a cultura francófona. Particularmente, era um leitor não só de Sartre mas também da literatura filosófica e literária existencialista em geral. Nesse sentido, acredito que uma das marcas de Goffman, que o distingue de outros autores da chamada Escola de Chicago, é essa visão como que trágica da interação, em que o risco de desencontro é mais enfatizado do que as possibilidades de sucesso da ação coletiva, de "doing things together" (Becker, 1977 e 1986). A vida social apresenta a dimensão de um jogo perigoso em que máscaras e espelhos não se harmonizam ou se complementam, como analisou, de modo arguto e talvez menos trágico, seu contemporâneo Anselm Strauss, cujas reflexões nada têm de otimismo ingênuo (Strauss, 1997).

A questão condutora de Goffman em Frame analysis é "o que está acontecendo aquil" ["what is it that's going on here"]. Trata-se da busca de frames que sustentem a definição de situação como aquela proposta por William Thomas e elaborada por Schutz, por sua vez acompanhando Wiliam James. Para Goffman, era importante não só reconhecer a definição de situação como real, mas também verificar como se chegou a ela e, sobretudo, identificar os frames que possibilitam ou viabilizam diferentes definições. Creio, assim, que se pode fazer uma aproximação, com as devidas cautelas, entre as noções de frame e de contexto, que permitiria uma compreensão mais completa do processo de construção social da realidade, introduzindo variáveis como poder no seu sentido mais amplo.

A contribuição de Ichheiser para as reflexões de Goffman é, principalmente, sublinhar e analisar situações de desencontro interacional, de falsa percepção social, acentuando as diferenças entre os atores envolvidos na negociação da realidade. A organização da experiência se dá através de processos de interação que dependem de frames e bases cognitivo-afetivas. Penso que se aproximam também da noção de web of meanings ("rede de significados") de Clifford Geertz, explicitamente influenciado por Schutz (Geertz, 1973). As ações e as condutas são permanentemente sujeitas a interpretações de diferentes atores sociais, a partir de variados pontos de vista e perspectivas. Nas sociedades moderno-contemporâneas, esse processo ficará 
mais evidente e agudo em função de sua complexidade sociológica e heterogeneidade cultural. Assim, ao mesmo tempo em que se recupera a noção de sujeito, esta é relativizada ao compreendê-la por meio de contextos interacionais e de quadros sociologicamente delineáveis. A preocupação com quem fala, de quem e para quem aponta para a tensão e dinâmica permanente dos discursos e falas sobre a ação social e a própria apresentação do self. O trânsito entre os diferentes mundos e províncias de significado fica mais evidente em sociedades onde coexistem correntes de tradição cultural diversificadas, em relações complexas e contraditórias (Barth, 1989). Os atores, mais ou menos sujeitos conscientes de seus projetos e condutas em geral, estarão sempre vivendo riscos de desencontro e julgamentos equivocados.

Portanto, esses diferentes pontos de vista e perspectivas dos atores interagindo em situações específicas, assim como suas possibilidades de negociação, remetem, num nível, à temática sociocultural mais ampla e, em outro, à questão existencial básica da relação do self com o outro. É evidente que a obra de Goffman visita e explora questões de diferentes tradições intelectuais. Ao fazê-lo, estimula diálogos interdisciplinares, sobretudo, por conta das dúvidas que levanta e impasses que destaca.

\section{Nota}

1 Consultado no site <http://www.sv.uit.no/ seksjon/psyk/floydartikkel12.html>, 1/11/2007.

\section{BIBLIOGRAFIA}

BARTH, Fredrik. (1989), "The analysis of culture in complex societies". Ethos, 54 (III-VI): 120142, Suécia.

BATESON, Gregory. (1972), Steps to an ecology of mind. Chicago, The University of Chicago Press.

BECKER, Howard S. (1977), Uma teoria da ação coletiva. Rio de Janeiro, Zahar. (1986), Doing things together. Evanston, Illinois, Northwestern University Press. (1996), "A Escola de Chicago". Mana: Estudos de Antropologia Social, 2 (2): 177-188, out.

BULMER, Martin. (1984), The Chicago School of Sociology: institutionalization, diversity and the rise of sociological research. Chicago, The University of Chicago Press.

GEERTZ, Clifford. (1973), The interpretation of cultures, Nova York, Basic Books [trad. bras.: A interpretação das culturas, Rio de Janeiro, Zahar, 1978].

GOFFMAN, Erving. (1959), The presentation of self in everyday life. Nova York, Doubleday, Anchor Books [trad. bras.: A representação do eu na vida cotidiana, Petrópolis, Vozes, 1975.]. (1974), Frame analysis: an essay on the organization of experience. Nova York, Harper Colophon Books.

ICHHEISER, Gustav. (1949), "Misunderstandings in human relations: a study in false social perception". The American Journal of Sociology. LV: 1-69, july 1949-may 1950, Chicago, The University of Chicago Press.

JAMES, William. ([1890] 1950), Principles of psychology. Nova York, Dover Publications.

SCHUTZ, Alfred. (1970-1971), Collected papers. The Hague, Martius Nijhoff, 3 vols. . (1979), Fenomenologia e relações sociais. Rio de Janeiro, Zahar.

SIMMEL, Georg. (1964), Conflict. Trad. Kurt H. Wolff. Nova York, The Free Press. (1971), On individuality and social forms. Coletânea organizada por Donald Levine, Chicago, The University of Chicago Press.

STRAUSS, Anselm. (1997), Espelhos e máscaras: a busca de identidade. São Paulo, Edusp.

THOMAS, William. (1966), On social organization and social personality. Selected papers. Chicago, The University of Chicago Press.

VALLADARES, Licia do Prado (org.). (2005), Escola de Chicago: impacto de uma tradição no Brasile na França. Belo Horizonte/Rio de Janeiro, Editora da UFMG/Iuperj. 


\section{GOFFMAN, MAL-ENTENDIDOS E RISCOS INTERACIONAIS}

\section{Gilberto Velho}

Palavras-chave: Interacionismo; Fenomenologia; Mal-entendido; Subjetividade.

O texto analisa as possíveis influências do fenomenólogo austríaco Gustav Ich heiser sobre a obra de Erving Goffman. Enfatiza-se, sobretudo, a dimensão de insucesso e de mal-entendidos nas relações sociais e individuais. Estabelecemse pontes com a noção de negociação da realidade e com outros autores relevantes para o desenvolvimento dessa linha de reflexão, como Georg Simmel, William James, William Thomas e Alfred Schutz.

\section{GOFFMAN,} MISUNDERSTANDINGS, AND INTERNATIONAL RISKS

\section{Gilberto Velho}

Keywords: Interactionism; Phenomenology; Misunderstanding; Subjectivity.

The paper analyses the possible influences of the Austrian phenomenologist Gustav Ichheiser on the work of Erving Goffman. It emphasizes, mainly, the scope of failure and misunderstandings in both social and individual relations. We establish connections to the notion of negotiation of the reality and to other relevant authors towards the development of this line of reflection, such as Georg Simmel, William James, William Thomas, and Alfred Schutz.

\section{GOFFMAN, MALENTENDUS} ET RISQUES INTERACTIFS

\section{Gilberto Velho}

Mots-clés: Interactivité; Phénoménologie; Malentendu; Subjectivité.

Le texte analyse les possibles influences du phénoménologue autrichien Gustav Ichheiser sur l'œuvre d'Erving Goffman. Il rappelle surtout la dimension d'insuccès et de malentendus dans les relations sociales et individuelles. Des ponts s'établissent avec la notion de négociation de la réalité et avec d'autres auteurs importants pour le développement de ce courant de réflexion, tels Georg Simmel, William James, William Thomas et Alfred Schutz. 